\title{
The Landscape of Comparative Politics: Which Regions and Countries Have Had High Profiles in Comparative Politics Journals?
}

Yoonjin Song, Gyeongsangbuk-do

ABSTRACT This article uses descriptive statistics and social-network analysis to examine which regions and countries were selected in studies comparing-two countries that have been published in America's renowned academic journals in comparative politics (CP): Comparative Political Studies and Journal of Comparative Politics. Which regions and countries are favored (and disfavored) by these studies? Analysis shows that the US-based CP journals strongly favor research on the countries of Western Europe and North America. There may be several explanations for this, but the uneven distribution of research publications with respect to continents and countries may be a source of several biases that should be of concern in the CP field.

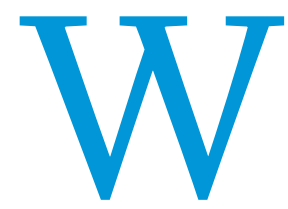

hich regions and countries have come to the foreground in comparative politics (CP) in the past quarter-century? This study examined which geographical areas and which countries have had a high profile in CP. All characters onstage are valuable, else they would not appear, but all do not hold center stage. Similarly, in the CP field, all geographical regions and countries should be studied, even though they may be smaller and less populous. In the two major journals in the field, however, it is likely that many geographical regions and countries are neglected. Thus, this article examines which geographical regions and countries have been studied for comparative case studies in the US-based CP journals Comparative Political Studies (CPS) and Journal of Comparative Politics (JCP) from 1990 to 2015 .

\section{THE PROBLEM OF REGIONAL AND COUNTRY BIAS}

Munck and Snyder $(2007,339)$ conducted research on authorship in the US-based CP journals. They found "the dearth of articles by foreign-based scholars" in main US-based academic journals including Comparative Politics, CPS, and World Politics. They argued that this seems to be against "openness" and "pluralism," which are intrinsic and valued attributes of CP that is "a field that

Yoonjin Song is a civil servant in the Division of Dokdo Policy, Maritime and Fishery Bureau, Pan East Sea Regional Headquarters at Gyeongsangbuk-do in Korea. He also worked with Dr. Daniel S. Geller as an International Fellow in the Department of Political Science at Wayne State University. He can be reached at yosong97@gmail.com. aspires to study the world" (Munck and Snyder 2007, 339). In a sense, "this [dominant] U.S.-centric perspective" shows a gap between as-it-is and as-it-ought-to-be in CP.

This article argues that the scarcity of foreign-based scholars publishing in US-based CP journals also is likely to be reflected in regions and countries that $\mathrm{CP}$ scholars choose to study. In particular, they tend to focus on specific regions and countries for their comparative study. This is evidence of "the [presumable] parochialism of research in comparative politics," which Munck and Snyder (2007, 341) strongly criticized. Further evidence of parochialism in $\mathrm{CP}$ would exist if the two renowned $\mathrm{CP}$ journals show a similar bias in the distribution of countries and regions of interest.

\section{METHODS}

To determine if there is such a bias, this study analyzed a total of 118 "comparing-two-country" articles published in JCP and CPS. The articles span the years 1990 through 2015. For JCP, there are 57 articles, including 46 country-monads or single-country studies and 48 country-dyads or studies of country pairs. For $C P S$, there are 61 articles, including 55 country-monads and 47 country-dyads. Overall, including both journals, and considering the overlap of single countries and country pairs, there is a total of 72 monads and 80 dyads. Table 1 shows the number of monads and dyads appearing in JCP alone, CPS alone, and in both JCP and CPS from 1990 to 2015 .

To analyze potential bias, I first reviewed the single-country studies, using graphics to examine the distribution of regions and countries within regions. I next looked at the two-country studies, 
determining whether the countries are from the same region and, if so, whether they are adjacent to one another. I conducted social-network analysis to provide a picture of the landscape of two-country studies.

\section{FINDINGS: MONAD ANALYSIS}

Regions are categorized according to the United Nations Regional Groups of Member States, as follows: African Group (AF), Asia-Pacific Group (AP), Eastern European Group (EAU), Latin of countries within regional groups. It shows that studies in $\mathrm{CP}$, regardless of region, have been heavily weighted in favor of certain countries.

First, in the case of WEU representing $42 \%$ of published articles, four countries (i.e., United States, United Kingdom, France, and Germany) accounted for $70 \%$ of articles about this region. Second, in the case of LAC representing $21 \%$ of all published articles, five countries (i.e., Brazil, Argentina, Mexico, Costa Rica, and Chile) accounted for $66 \%$ of articles about this region. Third, in the case

\section{First, in the case of WEU representing $42 \%$ of published articles, four countries (i.e., United States, United Kingdom, France, and Germany) accounted for $70 \%$ of articles about this region.}

American and Caribbean Group (LAC), and Western European and Others Group (WEU). ${ }^{1}$ As shown in figure $1,42 \%$ of published articles in JCP and CPS during the period of study focused on WEU, which includes the North American and Oceanic countries of the United States, Canada, Australia, and New Zealand. Conversely, AF and EAU each counted for only $8 \%$. WEU clearly is the focus of a large plurality of studies.

Figure 2 shows the distribution of countries by separate regions. The unequal distribution is paralleled by the unequal distribution

\section{Table 1}

Monad and Dyad Countries Appearing in JCP and CPS, 1990-2015

\begin{tabular}{lcccc} 
& JCP & CPS & Both JCP \& CPS (overlapped) & Total \\
\hline Monad & 46 & 55 & 29 & 72 \\
\hline Dyad & 48 & 47 & 15 & 80 \\
\hline
\end{tabular}

\section{Figure 1}

Distribution of Regional Groups as the Focus of Published Papers

\section{Distribution of Regional Groups}

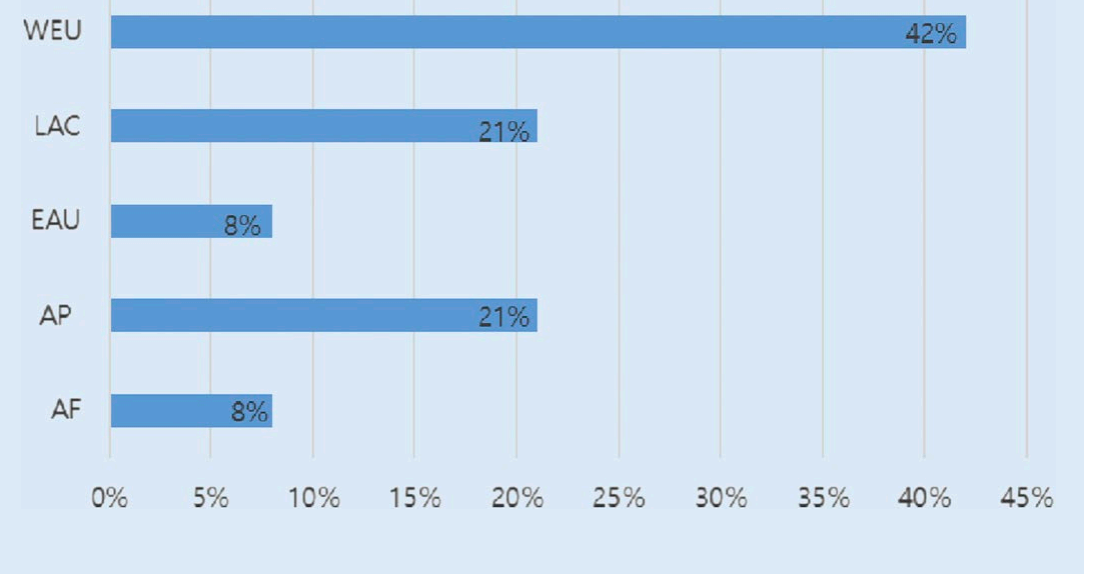

of AF representing $8 \%$ of all published articles, five countries (i.e., South Africa, Kenya, Rwanda, Zimbabwe, and Côte d'Ivoire) accounted for $75 \%$ of articles about this region. Fourth, in the case of AP representing $21 \%$ of all published articles during the same period, five nations (i.e., Korea, Taiwan, India, Japan, and China) accounted for $66 \%$ of articles about this region. Fifth, in the case of EAU, with only $8 \%$ of all published articles, four countries (i.e., Russia, Poland, Hungary, and Ukraine) accounted for $83 \%$ of EAU-related articles. As shown in figures 1 and 2, publications in these two leading journals focused disproportionately on certain regions and countries within particular regions, suggesting both regional and country biases.

\section{FINDINGS: DYAD ANALYSIS}

Many CP scholars-by choice (e.g., nationality, graduate training, country or research interests) and for practical concerns (e.g., language skills, research funds, and time)-are specialists in either the politics of a single country or, at best, a few countries. Are these constraints reflected in the focus of published research and therefore a source of bias in $\mathrm{CP}$ ? When two countries are compared, are the countries from the same or different regions? Table 2 shows the distribution of country-dyads across regions. A country-dyad can include countries from the same or different regions. It is apparent that country-dyads most often include countries from the same region-indeed, these pairs comprised more than two thirds of the country-dyad studies $(88 / 118=74.6 \%)$. WEUWEU dyads garnered a $37.3 \%(44 / 118=37.3 \%)$ share of all two-country CP articles. They also had a $50 \%(44 / 88=50 \%)$ share of articles dealing with symmetric dyads. In contrast, AF-AF and EAU-EAU dyads received much less attention: each garnered a $6 \%$ percent $(6 / 118=5 \%)$ share.

When two countries from the same region are compared, are they adjacent to one another? It is possible that CP scholars favor the most similar system design that a half-century ago was recommended by Przeworski and Teune (1970). Countries from the same region that are adjacent to one another are more likely to share 


\section{Figure 2}

\section{Distribution of Countries by Regions as the Focus of Published Papers}
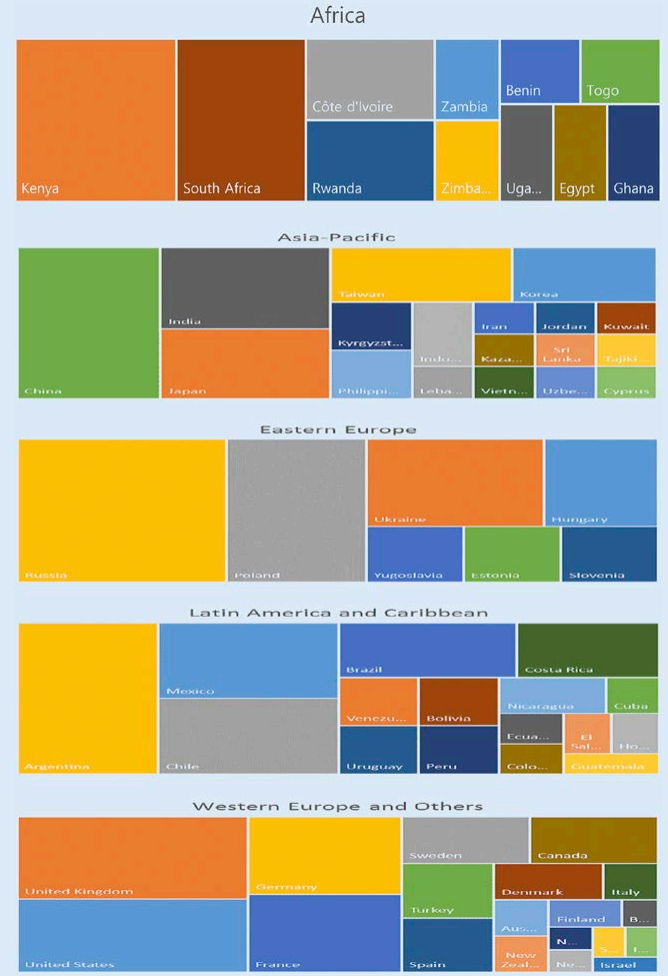

similar characteristics, allowing for the control of extraneous factors, making comparison easier.

There also may be practical reasons (e.g., easier access and limited research resources) for comparing adjacent countries. Table 2 shows how often specific country pairs have been published in two-country CP studies. As shown, the same continental neighbors-including fr-uk (7); cn-in (6); ca-us (5); ar-cl (4); ar-br (3); jp-us (3); ru-ua (3); se-uk (3); and uk-us (3)-appear more frequently as the objects of $\mathrm{CP}$ study.

In summary, monadic studies involving countries from the WEU region and country-dyad studies involving two countries from this region (see figure 3) are the most frequently published studies. At the monad level, the United Kingdom, the United States, Germany, France, Argentina, and China appear most frequently. At the dyad level, France-United Kingdom, China-India, Canada-United States, Argentina-Chile, and Germany-United States are the preferred research subjects. In particular, the United Kingdom appeared as the most preferred country and France-United Kingdom as the most preferred country pair in $J C P$ and CPS. Plainly, there is an uneven distribution of countries and country pairs in CP studies, as well as an uneven distribution of countries within regional groups. Based on social-network analysis, figure 4 depicts this uneven distribution of two-country $\mathrm{CP}$ studies. The related data are shown in table 3.

\section{IMPLICATIONS}

This study examined the extent to which different regions and countries appeared as the focus of articles published in the two major CP journals: JCP and CPS. It addressed the question of which countries and regions are favored (and disfavored) by studies published in these US-based journals. It found that for both journals, there is similarity in the distribution of countries and regions of interest. Specific regions and specific countries within regions are favored. Finally, specific pairs of countries are favored in studies of the same region. This is evidence of parochialism and bias in the representation of both regions and countries in CP.

Several questions, however, remain unanswered and are beyond the scope of this study. What might account for these findings? There are several plausible explanations that are not mutually exclusive. The bias in representation of regions and countries may be due in part to the distribution of CP scholars, with more specialists residing in the United States and Western Europe. Perhaps there is more vigorous competition by these US and Western European specialists to publish in the top CP journals, resulting in more and higher-quality submissions. It may

Table 2

\section{Distribution of Paired Countries Appearing in Two-Country Comparative Studies 3}

Dyad (number of published articles) 80 dyads, 118 articles

JCP (number of published articles) 48 dyads, 57 articles

CPS (number of published articles) 47 dyads, 61 articles

\begin{tabular}{lll}
7 fr-uk & fr-uk (3) & fr-uk (4) \\
\hline 6 cn-in & cn-in (3) & cn-in (3) \\
\hline 5 ca-us & ca-us (1)
\end{tabular}

4 ar-cl; de-us

ar-cl (2); de-us (1)

ar-cl (2); de-us (3)

3 ar-br; jp-us; ru-ua; se-uk; uk-us

2 au-nz; cl-mx; cn-tw; de-uk; fr-de; kr-tw; mx-ve; pl-ru

$\mathbf{1}$ ar-mx; ar-pl; ar-tr; ar-uy; at-us; be-dk; bj-tg; bo-ec; bo-id; br-es; br-mx; ca-za; ci-gh; ch-jp; ci-ke; cl-es; cl-uy; cn-hu; cn-ru; cn-vn; co-pe; cr-ni; cl-za; cu-hu; cy-es; de-in; de-pl; de-se; de-tr; dk-nl; dk-no; dk-se; ee-si; eg-tr; es-it; es-fr; fi-ie; fi-il; fr-se; fr-us; gt-hn; id-ph; ir-tr; it-uk; jo-kw; jp-kr; jp-tw; ke-mx; ke-rw; ke-za; ke-zw; kr-zm; kz-kg; lb-uk; lk-yu; pe-ph; rw-ug; sv-za; tj-uz; tr-uk; uk-za 
Figure 3

Distribution of Paired Regional Groups Appearing in the Two-Country Comparative Studies

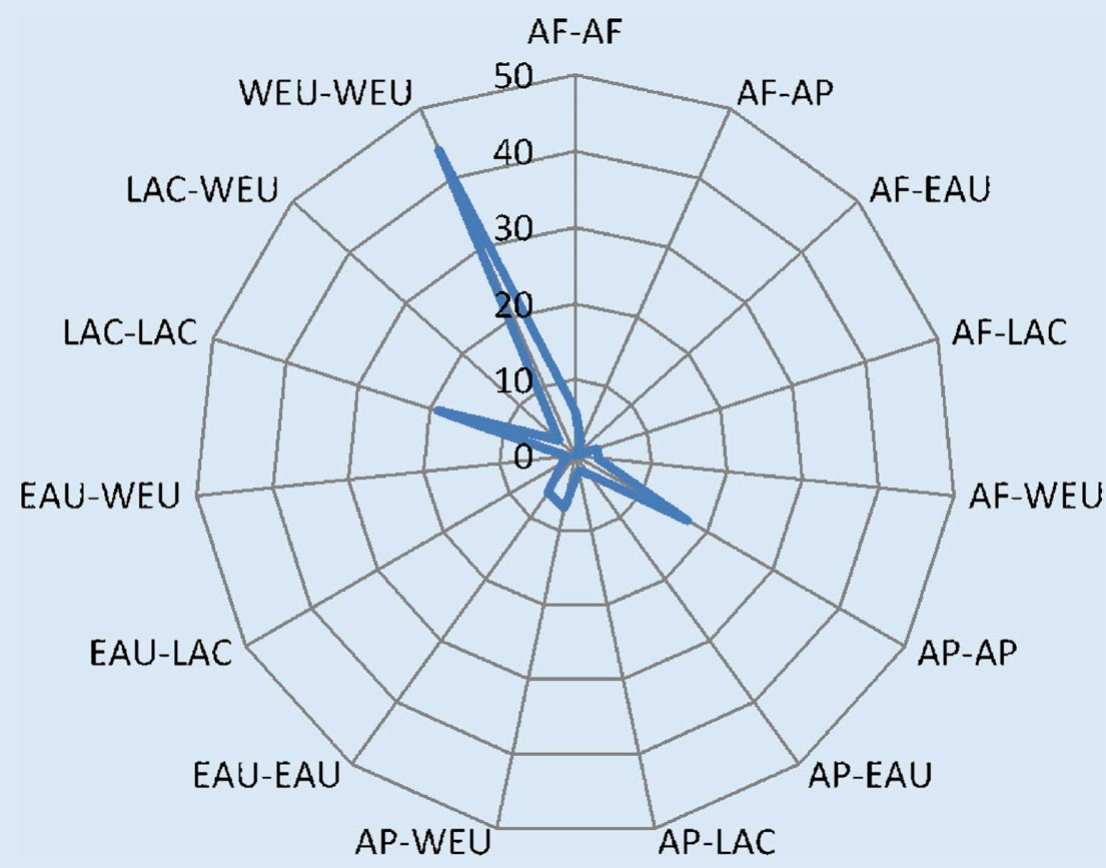

Figure 4

Social Network Visualization: Landscape of Two-Country Comparative Studies

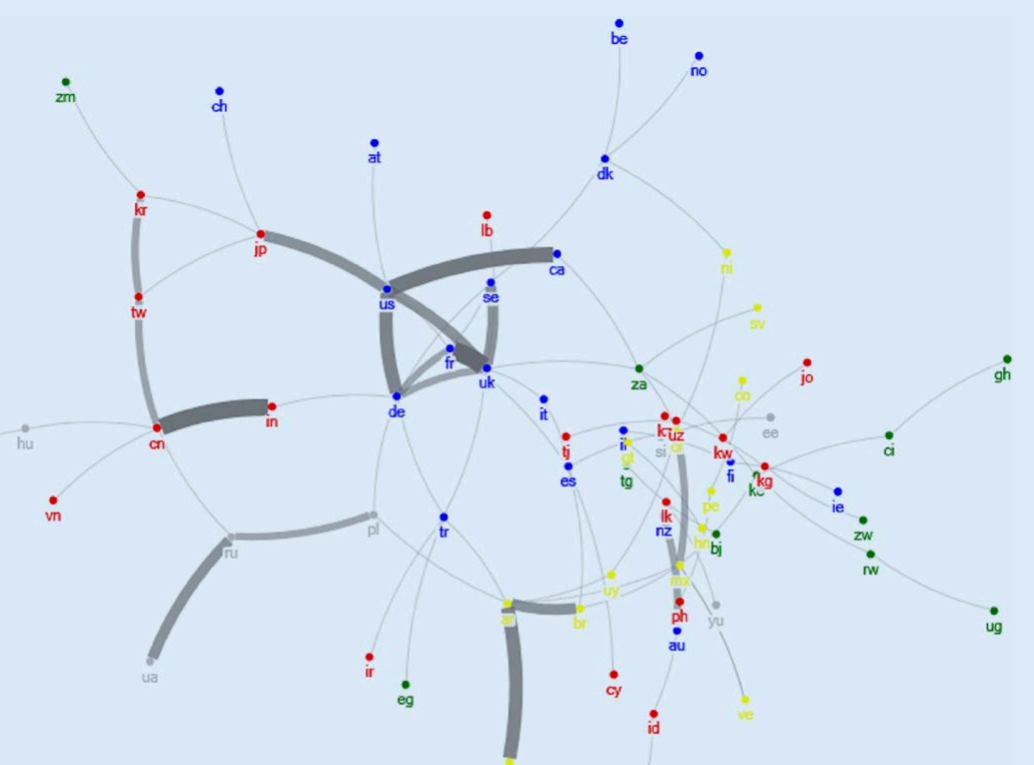

be due in part to the existence of regional journals in which area specialists prefer to publish. They may believe that if their manuscripts are sent to a regional journal, they will receive more knowledgeable and helpful reviews and, if published, will be more widely read and cited.

There may be other explanations. Perhaps data are more readily available or easier to gather from some countries and regions than others. Finally, what $\mathrm{CP}$ scholars regard as the more important questions in their subfield may be better studied by focusing on some countries and regions. Thus, editors and reviewers might be making judgments about the quality of a manuscript based on their understanding of the field of $\mathrm{CP}$ and a decision on whether the manuscript is addressing a significant question and making an important contribution to theory.

A provocative explanation is that the bias is in part a legacy of colonialism. If Western European scholars, in particular, are specialists in countries and regions outside of the WEU region, their choice of countries and regions is based in part on their home country's colonial history. Further research is necessary to determine the relevance of these potential explanations.

What is the significance of these biases for the field of CP? It seems to depend on what explains these biases. If the biases reflect the distribution of scholars, it is arguable that there is too much scholarly attention given to some countries and regions and too little to others. Specialists in countries and regions that are crowded with scholars, where there are more submissions, likely will experience more competition to publish. Indeed, these scholars already may have answered most of the important questions. As a result, scholars' 
Table 3

Social Network Analysis: Landscape of Two-Country Comparative Studies

\begin{tabular}{|c|c|c|c|c|c|c|c|}
\hline Vertex & Country Name & Regional Group & Degree & Betweenness Centrality* & Closeness Centrality & Eigenvector Centrality & Clustering Coefficient \\
\hline uk & United Kingdom & WEU & 8 & 270.0 & 0.009 & 0.104 & 0.200 \\
\hline de & Germany & WEU & 7 & 231.7 & 0.008 & 0.097 & 0.300 \\
\hline us & United States & WEU & 6 & 212.4 & 0.008 & 0.076 & 0.200 \\
\hline ar & Argentina & LAC & 6 & 171.7 & 0.007 & 0.033 & 0.100 \\
\hline za & South Africa & AF & 5 & 217.1 & 0.008 & 0.039 & 0.000 \\
\hline $\mathrm{cn}$ & China & AP & 5 & 155.9 & 0.006 & 0.010 & 0.000 \\
\hline $\operatorname{tr}$ & Turkey & WEU & 5 & 126.9 & 0.007 & 0.057 & 0.100 \\
\hline$m x$ & Mexico & LAC & 5 & 120.9 & 0.006 & 0.021 & 0.100 \\
\hline es & Spain & WEU & 5 & 94.7 & 0.007 & 0.037 & 0.000 \\
\hline $\mathrm{cr}$ & Costa Rica & LAC & 5 & 92.3 & 0.007 & 0.025 & 0.000 \\
\hline $\mathrm{fr}$ & France & WEU & 5 & 91.6 & 0.008 & 0.083 & 0.500 \\
\hline ke & Kenya & $\mathrm{AF}$ & 4 & 178.5 & 0.006 & 0.015 & 0.000 \\
\hline se & Sweden & WEU & 4 & 164.0 & 0.007 & 0.066 & 0.500 \\
\hline jp & Japan & AP & 4 & 140.1 & 0.006 & 0.021 & 0.167 \\
\hline $\mathrm{dk}$ & Denmark & WEU & 4 & 129.0 & 0.006 & 0.017 & 0.000 \\
\hline $\mathrm{pl}$ & Poland & EAU & 3 & 129.3 & 0.007 & 0.030 & 0.000 \\
\hline ru & Russia & EAU & 3 & 95.2 & 0.006 & 0.009 & 0.000 \\
\hline $\mathrm{kr}$ & Korea & AP & 3 & 44.0 & 0.005 & 0.007 & 0.333 \\
\hline tw & Taiwan & $\mathrm{AP}$ & 3 & 35.7 & 0.006 & 0.008 & 0.333 \\
\hline $\mathrm{br}$ & Brazil & LAC & 3 & 20.1 & 0.007 & 0.020 & 0.333 \\
\hline in & India & AP & 2 & 90.8 & 0.007 & 0.023 & 0.000 \\
\hline $\mathrm{ci}$ & Côte d'Ivoire & LAC & 2 & 44.0 & 0.005 & 0.003 & 0.000 \\
\hline hu & Hungary & EAU & 2 & 44.0 & 0.005 & 0.002 & 0.000 \\
\hline rw & Rwanda & $\mathrm{AF}$ & 2 & 44.0 & 0.005 & 0.003 & 0.000 \\
\hline $\mathrm{ca}$ & Canada & WEU & 2 & 32.7 & 0.007 & 0.025 & 0.000 \\
\hline uy & Uruguay & LAC & 2 & 10.3 & 0.006 & 0.013 & 0.000 \\
\hline id & Indonesia & AP & 2 & 6.0 & 0.111 & 0.000 & 0.000 \\
\hline ph & Philippines & AP & 2 & 6.0 & 0.111 & 0.000 & 0.000 \\
\hline it & Italy & WEU & 2 & 4.2 & 0.007 & 0.031 & 0.000 \\
\hline bo & Bolivia & LAC & 2 & 4.0 & 0.091 & 0.000 & 0.000 \\
\hline pe & Peru & LAC & 2 & 4.0 & 0.091 & 0.000 & 0.000 \\
\hline $\mathrm{fi}$ & Finland & WEU & 2 & 1.0 & 0.500 & 0.000 & 0.000 \\
\hline $\mathrm{kg}$ & Kyrgyzstan & $\mathrm{AP}$ & 2 & 1.0 & 0.500 & 0.000 & 0.000 \\
\hline at & Austria & WEU & 1 & 0.0 & 0.006 & 0.017 & 0.000 \\
\hline $\mathrm{au}$ & Australia & WEU & 1 & 0.0 & 1.000 & 0.000 & 0.000 \\
\hline be & Belgium & WEU & 1 & 0.0 & 0.005 & 0.004 & 0.000 \\
\hline bj & Benin & $\mathrm{AF}$ & 1 & 0.0 & 1.000 & 0.000 & 0.000 \\
\hline ch & Switzerland & WEU & 1 & 0.0 & 0.005 & 0.005 & 0.000 \\
\hline $\mathrm{cl}$ & Chile & LAC & 1 & 0.0 & 0.005 & 0.007 & 0.000 \\
\hline co & Colombia & LAC & 1 & 0.0 & 0.067 & 0.000 & 0.000 \\
\hline cy & Cyprus & AP & 1 & 0.0 & 0.005 & 0.008 & 0.000 \\
\hline $\mathrm{cu}$ & Cuba & LAC & 1 & 0.0 & 0.004 & 0.001 & 0.000 \\
\hline ec & Ecuador & LAC & 1 & 0.0 & 0.067 & 0.000 & 0.000 \\
\hline ee & Estonia & EAU & 1 & 0.0 & 1.000 & 0.000 & 0.000 \\
\hline
\end{tabular}


Table 3 (Continued)

\begin{tabular}{|c|c|c|c|c|c|c|c|}
\hline Vertex & Country Name & Regional Group & Degree & Betweenness Centrality* & Closeness Centrality & Eigenvector Centrality & Clustering Coefficient \\
\hline eg & Egypt & $\mathrm{AF}$ & 1 & 0.0 & 0.006 & 0.012 & 0.000 \\
\hline gh & Ghana & $\mathrm{AF}$ & 1 & 0.0 & 0.004 & 0.001 & 0.000 \\
\hline gt & Guatemala & LAC & 1 & 0.0 & 1.000 & 0.000 & 0.000 \\
\hline hn & Honduras & LAC & 1 & 0.0 & 1.000 & 0.000 & 0.000 \\
\hline ie & Ireland & WEU & 1 & 0.0 & 0.333 & 0.000 & 0.000 \\
\hline il & Israel & WEU & 1 & 0.0 & 0.333 & 0.000 & 0.000 \\
\hline ir & Iran & AP & 1 & 0.0 & 0.006 & 0.012 & 0.000 \\
\hline jo & Jordan & AP & 1 & 0.0 & 1.000 & 0.000 & 0.000 \\
\hline $\mathrm{kw}$ & Kuwait & AP & 1 & 0.0 & 1.000 & 0.000 & 0.000 \\
\hline kz & Kazakhstan & AP & 1 & 0.0 & 0.333 & 0.000 & 0.000 \\
\hline lb & Lebanon & AP & 1 & 0.0 & 0.006 & 0.023 & 0.000 \\
\hline Ik & Sri Lanka & AP & 1 & 0.0 & 1.000 & 0.000 & 0.000 \\
\hline ni & Nicaragua & LAC & 1 & 0.0 & 0.005 & 0.006 & 0.000 \\
\hline $\mathrm{nl}$ & Netherlands & WEU & 1 & 0.0 & 0.005 & 0.004 & 0.000 \\
\hline no & Norway & WEU & 1 & 0.0 & 0.005 & 0.004 & 0.000 \\
\hline $\mathrm{nz}$ & New Zealand & WEU & 1 & 0.0 & 1.000 & 0.000 & 0.000 \\
\hline si & Slovenia & EAU & 1 & 0.0 & 1.000 & 0.000 & 0.000 \\
\hline sv & EI Salvador & LAC & 1 & 0.0 & 0.006 & 0.009 & 0.000 \\
\hline $\operatorname{tg}$ & Togo & $\mathrm{AF}$ & 1 & 0.0 & 1.000 & 0.000 & 0.000 \\
\hline tj & Tajikistan & AP & 1 & 0.0 & 1.000 & 0.000 & 0.000 \\
\hline ua & Ukraine & EAU & 1 & 0.0 & 0.005 & 0.002 & 0.000 \\
\hline ug & Uganda & $\mathrm{AF}$ & 1 & 0.0 & 0.004 & 0.001 & 0.000 \\
\hline $\mathrm{uz}$ & Uzbekistan & AP & 1 & 0.0 & 1.000 & 0.000 & 0.000 \\
\hline ve & Venezuela & LAC & 1 & 0.0 & 0.005 & 0.005 & 0.000 \\
\hline vn & Viet Nam & $\mathrm{AP}$ & 1 & 0.0 & 0.005 & 0.002 & 0.000 \\
\hline yu & Yugoslavia & EAU & 1 & 0.0 & 1.000 & 0.000 & 0.000 \\
\hline $\mathrm{zm}$ & Zambia & $\mathrm{AF}$ & 1 & 0.0 & 0.004 & 0.001 & 0.000 \\
\hline$z w$ & Zimbabwe & $\mathrm{AF}$ & 1 & 0.0 & 0.333 & 0.000 & 0.000 \\
\hline
\end{tabular}

*Rounded to one decimal place

efforts are spent finding answers to questions that, although still interesting, are less important. If the explanation is due to regional specialists sending manuscripts to regional journals, however, this may reflect a beneficial division of labor in CP.

Questions that are important to specialists in the politics of the United States and Western Europe, for example, are not likely to be important to specialists in the politics of other countries and regions. If the reason is that data are more readily available or easier to gather from some countries and regions, there is reason to think about why this is so and, if possible, to find solutions, such as increased funding for cross-national survey research (e.g., World Values Surveys) and large-scale CP data-collection efforts.

\section{CONCLUSION}

This study examined the extent to which different regions and countries appeared as the focus of the major US-based CP journals from 1990 to 2015. The major finding is the disproportionate representation of particular regions and countries. Some regions and countries have been over-valued and over-researched; others have been under-valued and under-researched. A conjecture is that the uneven distribution of concern reflects in part a lingering colonialist attitude. For some CP scholars, there are countries and regions that weigh more heavily in the calculus of what is and is not important.

\section{ACKNOWLEDGMENTS}

I express my heartfelt thanks to my professors, Dr. Daniel S. Geller, Dr. Lawrence Alvin Scaff, and Dr. John Martin Strate, for their unstinting encouragement and support. Dr. Strate made helpful comments in the development of this article. I also thank Dr. Kevin Deegan-Krause for his suggestion.

\section{NOTES}

1. See www.un.org/depts/DGACM/RegionalGroups.shtml.

2. For countries appearing only in $J C P: 17$ countries including bj(Benin), co(Colombia), cu(Cuba), ec(Ecuador), hu(Hungary), ir(Iran), jo(Jordan), kg(Kyrgyzstan), kw(Kuwait), kz(Kazakhstan), lb(Lebanon), rw(Rwanda), tg(Togo), ug(Uganda), vn(Viet Nam), zm(Zambia), and zw(Zimbabwe), For countries appearing only in CPS: 26 countries including at(Austria), 
au(Australia), be(Belgium), ch(Switzerland), cr(Costa Rica), су(Cyprus), ee(Estonia), eg(Egypt), fi(Finland), gh(Ghana), gt(Guatemala), hn(Honduras), id(Indonesia), ie(Ireland), il(Israel), lk(Sri Lanka), ni(Nicaragua), nl(Netherlands), no(Norway), nz(New Zealand), ph(Philippines), si(Slovenia), sv(El Salvador), tj(Tajikistan), uz(Uzbekistan), and yu(Yugoslavia). For countries appearing in both journals: 29 countries including ar(Argentina), bo(Bolivia), br(Brazil), ca(Canada), ci(Côte d'Ivoire), cl(Chile), cn(China), de(Germany), dk(Denmark), es(Spain), fr(France), in(India), it(Italy), jp(Japan), ke(Kenya), kr(Korea), mx(Mexico), pe(Peru), pl(Poland), ru(Russia), se(Sweden), tr(Turkey), tw(Taiwan), ua(Ukraine), uk(United Kingdom), us(United States), uy(Uruguay), ve(Venezuela), and za(South Africa).

3. uk(United Kingdom); de(Germany); us(United States); ar(Argentina); za(South Africa); cn(China); $\operatorname{tr}($ Turkey); $\operatorname{mx}($ Mexico); es(Spain); $\operatorname{cr}($ Costa Rica); fr(France); ke(Kenya); se(Sweden); jp(Japan); dk(Denmark); pl(Poland); ru(Russia); kr(Korea); tw(Taiwan); br(Brazil); in(India); ci(Côte d'Ivoire); hu(Hungary); rw(Rwanda); ca(Canada); uy(Uruguay); id(Indonesia); ph(Philippines); it(Italy); bo(Bolivia); pe(Peru); f(Finland); kg(Kyrgyzstan);
at(Austria); au(Australia); be(Belgium); bj(Benin); ch(Switzerland); cl(Chile); co(Colombia); cy(Cyprus); cu(Cuba); ec(Ecuador); ee(Estonia); eg(Egypt); gh(Ghana); gt(Guatemala); hn(Honduras); ie(Ireland); il(Israel); ir(Iran); jo(Jordan); kw(Kuwait); kz(Kazakhstan); lb(Lebanon); lk(Sri Lanka); ni(Nicaragua); nl(Netherlands); no(Norway); nz(New Zealand); si(Slovenia); sv(El Salvador); tg(Togo); tj(Tajikistan); ua(Ukraine); ug(Uganda); uz(Uzbekistan); ve(Venezuela); vn(Viet Nam); yu(Yugoslavia); zm(Zambia); and zw(Zimbabwe).

\section{REFERENCES}

Munck, Gerardo L., and Richard Snyder. 2007. "Who Publishes in Comparative Politics? Studying the World from the United States." PS: Political Science \& Politics 40 (2): 339-46.

Przeworski, Adam, and Henry J. Teune. 1970. The Logic of Comparative Social Inquiry. New York: John Wiley \& Sons. 